\title{
All-organic composites with strong photoelectric response over a wide spectral range
}

\author{
Jie Liu ${ }^{1 \dagger}$, Kewang $\mathrm{Yi}^{1 \dagger}$, Zhaopeng Wang ${ }^{1 \dagger}$, Zijie Zhang ${ }^{2}$, Yucong $\mathrm{Qi}^{2}$, Pan Chen ${ }^{1}$, \\ Qundong Shen ${ }^{2 *}$ and Baojin $\mathrm{Chu}^{1^{*}}$
}

\begin{abstract}
2-hydroxynaphthylidene-1'-naphthylamine (HNAN) and $-\mathrm{NO}_{2}$ modified HNAN $\left(\mathrm{HNAN}-\mathrm{NO}_{2}\right)$ Schiff base compounds were synthesized and exhibited strong visible light absorption $(<650 \mathrm{~nm})$. These compounds were added to poly(vinylidene fluoride-trifluoroethylene) (P(VDF-TrFE)) ferroelectric polymer, obtaining composites with high photoelectric response under visible and infrared light. It was found that the modification of HNAN by the nitro group and the poling of the composites under a high electric field can greatly enhance the photoelectric response of the composites. The composites can generate high photovoltages of 1386 and $352.7 \mathrm{mV}$ under irradiation with near-infrared light $(915 \mathrm{~nm})$ and green light $(532 \mathrm{~nm})$. The mechanism of the photoelectric response of the composites under green light was explored and it was found that the response originates mainly from the coupling effect of the photothermal effect of the Schiff base and the pyroelectric effect of the ferroelectric polymer. The composites, which can be utilized as photodetector materials, are promising for next-generation artificial retina applications and the sensing capability of retina can be extended in a wide wavelength range from visible to infrared light.
\end{abstract}

Keywords: all-organic composites, photoelectric response, photothermal effect, pyroelectric effect

\section{INTRODUCTION}

Photodetector materials that can convert light into electrical signal are important for a range of sensing applications in biological systems and electronic devices [1-9]. For example, high-performance photodetector materials are critical for the development of next-generation artificial retina systems $[10,11]$. Due to various retina diseases, such as macular hole and diabetic retinopathy, many people suffer from vision loss or even complete blindness. This has motivated the development of artificial retina systems in order to recover the vision of the patients suffering from retina diseases. The current commercial artificial retina systems are complex and require external power sources [12-14]. New artificial retina systems being developed are expected to be much simpler and they could be only composed of a layer of light-sensitive thin film implanted on the retina [15]. The thin film can directly convert light into electrical signal, which stimulates the optic nerve, and the photodetector film has a function resembling that of the real retina $[15,16]$. For use as artificial retina photodetectors, the photodetector materials should be flexible and display a photoelectric response in a wide range of light wavelengths that is sufficiently strong for the direct stimulation of neurons.

Conventional photodetector materials are usually designed based on the two common operational mechanisms of semiconductor materials. Photoconductive materials can detect light through the change in the conductivity of the material due to exposure to light $[17,18]$ and show good photosensitivity in a relatively wide spectral range [19-23]. Unlike photoconductors, photodiodes with heterojunction structures generate a photoelectric response directly under light irradiation based on the photovoltaic effect and do not require an external power source [24,25]. Compared with inorganic photodetector materials, organic photodetector materials have attracted increasing attention due to the advantages of flexibility, lower price, low weight, and easy processing and modification. Besides the semiconductive materials, insulating ferroelectric polymers have also been explored to design organic photodetector materials. In a recent study, the blend of poly(vinylidene

\footnotetext{
${ }^{1}$ CAS Key Laboratory of Materials for Energy Conversion and Department of Materials Science and Engineering, University of Science and Technology of China, Hefei 230026, China

${ }^{2}$ Department of Polymer Science and Engineering, School of Chemistry and Chemical Engineering, Nanjing University, Nanjing 210023, China

These authors contributed equally to this work.

* Corresponding authors (emails: chubj@ustc.edu.cn (Chu B); qdshen@nju.edu.cn (Shen Q))
} 
fluoride-trifluoroethylene) (P(VDF-TrFE) $)$ ferroelectric polymer and azobenzene polymer was investigated as the photodetector for artificial retina [15]. The photoelectric response of the blend arises from the polarization change of the copolymer via the coupling effect of the photoisomerization process of the light-sensitive azobenzene polymer and the piezoelectric or flexoelectric effect of the ferroelectric polymer [26-28]. The mechanism of the photoelectric response of the blend is different from that of the semiconductive photodetectors in which the response is caused by the generation and separation of electrons and holes under light illumination $[29,30]$. The ferroelectric polymer-based materials were found to exhibit a photoelectric response that is strong enough for direct communication with neuron cells and are promising for the use in next-generation artificial retina.

In this work, inspired by the work of Chen et al [15], photodetector composite materials based on the P(VDF$\mathrm{TrFE}$ ) ferroelectric polymer were designed and fabricated. Because the ferroelectric polymer is pyroelectric and only light-sensitive in the infrared (IR) wavelength range, another component that shows a response under visible light illumination is added to $\mathrm{P}(\mathrm{VDF}-\mathrm{TrFE})[31,32]$. Some Schiff bases and their metal complexes are light sensitive and have been exploited in organic photovoltaic devices [33-35]. In our study, two Schiff base compounds, namely, 2-hydroxynaphthylidene-1'-naphthyl-

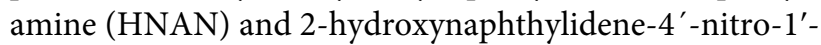
naphthylamine (HNAN-NO$)_{2}$, were synthesized and used as the fillers of the composites. We found that HNAN showed strong visible light absorption and the composites of HNAN and P(VDF-TrFE) exhibit strong photoelectric response under visible and IR light. We also show that the modification of HNAN by $-\mathrm{NO}_{2}$ enhances the light absorption, and the composite of $\mathrm{HNAN}-\mathrm{NO}_{2}$ and the polymer has an enhanced photoelectric response. The composites can generate a high voltage of $1386 \mathrm{mV}$ under IR light illumination, while under green light, for which human eye has the highest sensitivity, the materials can achieve a high voltage of $353 \mathrm{mV}$. Due to the strong photoelectric response, the composite materials may be utilized to design artificial retina systems. Furthermore, the materials have the response under both visible and IR light and this may expand the sensing capability of the retina compared with human eye.

\section{EXPERIMENTAL SECTION}

\section{Synthesis of Schiff base compounds}

HNAN was synthesized by refluxing a mixture of 2-hy- droxy-1-naphthaldehyde (Macklin Reagent Co., Ltd., Shanghai, China) and 1-naphthylamine (Macklin reagent Co. Ltd, Shanghai, China) in alcohol at $60^{\circ} \mathrm{C}$ for $5 \mathrm{~h}$. An orange precipitate was obtained by filtering and repeatedly washing the reaction product with alcohol. HNAN- $\mathrm{NO}_{2}$ was prepared by first dissolving 4-nitro-1naphthylamine (Energy Chemical Co., Ltd., Shanghai, China) in alcohol at $50^{\circ} \mathrm{C}$ and filtering out the insoluble matter. The solution was heated to $70^{\circ} \mathrm{C}$ and 2-hydroxy1-naphthaldehyde was added. The refluxing of the mixture was performed at $70^{\circ} \mathrm{C}$ for $5 \mathrm{~h}$. A red precipitate was obtained by filtering and washing with alcohol. The reaction products were dried in vacuum oven at $50^{\circ} \mathrm{C}$ for $12 \mathrm{~h}$. The corresponding chemical reactions are shown in Fig. 1a.

\section{Fabrication of composites film}

$\mathrm{P}(\mathrm{VDF}-\mathrm{TrFE})$ (70/30) was purchased from Piezotech (France). P(VDF-TrFE) (0.396 g) was added into $N, N$ dimethylformamide (DMF) (Sinopharm Chemical Reagent Co., Ltd., Shanghai, China) and stirred overnight. HNAN or HNAN-NO $\mathrm{N}_{2}$ powder $(4 \mathrm{mg})$ was blended with the $\mathrm{P}(\mathrm{VDF}-\mathrm{TrFE})$ solution, and then the solution was cast on a glass plate after thorough stirring and dried at $90^{\circ} \mathrm{C}$ for $2 \mathrm{~h}$. The composite film was annealed in a vacuum oven at $120^{\circ} \mathrm{C}$ for $5 \mathrm{~h}$.

\section{Characterization methods}

Nuclear magnetic resonance (NMR) spectra were recorded using a Bruker Avance AV400 NMR spectrometer (Bruker, Karlsruhe, Germany). The synthesized products were dissolved in dimethylsulfoxide-D6 (DMSO-D6). The Fourier-transform infrared spectra (FTIR) of the samples were obtained using a Thermo Fisher-Nicolet 6700 FTIR spectrometer (Nicolet, Madison, WI, USA). The ultraviolet-visible-near infrared (UV-Vis-NIR) spectra were recorded using a JASCO V-670 spectrophotometer (JASCO Co. Ltd., Hachioji City, Tokyo, Japan). The scanning electron microscopy (SEM) images were characterized by a SU8220 field emission scanning electron microscope (FE-SEM) (HITACHI, Japan). The temperature of the composite films under light illumination was recorded using a Fotric $226 \mathrm{~S}$ infrared camera. To measure the photoelectric response, circular gold electrodes with a diameter of $6 \mathrm{~mm}$ were coated on both sides of the samples by direct current (DC) sputtering using a sputter coater (EMS150T, Electron Microscopy Sciences, Hatfield, PA, USA). The photovoltage of the samples was measured using an electrochemical workstation (CHI $800 \mathrm{~B}, \mathrm{CH}$ Instruments, Inc.) under illumination by the 


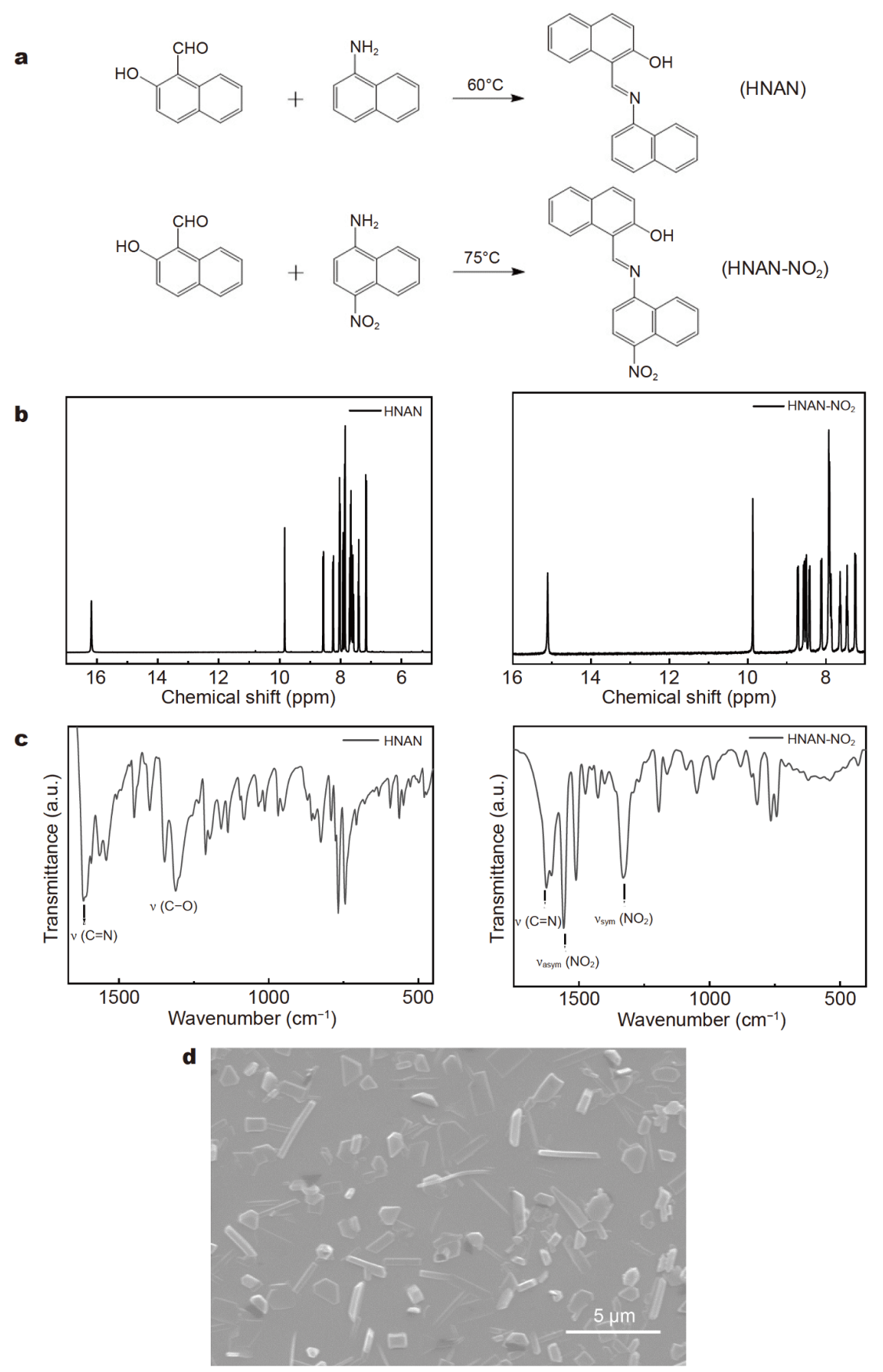

Figure 1 Preparation and characterization of the Schiff base compounds and the composites. (a) Chemical reactions of $\mathrm{HNAN}$ and $\mathrm{HNAN}^{-\mathrm{NO}_{2}}$. (b) ${ }^{1} \mathrm{H}-\mathrm{NMR}$ spectra of HNAN and HNAN-NO . The samples were dissolved in DMSO-d6 and their spectra were measured at $400 \mathrm{MHz}$. (c) FTIR spectra of HNAN and HNAN-NO ${ }_{2}$ (d) SEM image of the surface of HNAN/P(VDF-TrFE) composite, showing the rod-like shape of the HNAN.

near-infrared (wavelength of $915 \mathrm{~nm}$, Beijing Laserwave Optoelectronics, Beijing, China) and green (wavelength $532 \mathrm{~nm}$, Guangzhou MTO-laser, Guangzhou, China) lasers from one side of the film for $10 \mathrm{~s}$ in a dark box. The setup of the photoelectric measurements is schematically shown in Fig. S1. For the dielectric measurements, gold electrodes were coated on both sides of the film to form a metal-insulator-metal (MIM) structure. The dielectric properties were obtained using an LCR meter (Agilent E4980A, Agilent Technologies, Santa Clara, CA, USA) 
equipped with a controllable furnace, as schematically shown in Fig. S2. The pyroelectric voltages of the samples were measured by an electrometer (Keithley 6517A, Tektronix Inc., Beaverton, OR, USA) while the composites were heated in a furnace at a heating rate of $2^{\circ} \mathrm{C} \min ^{-1}$.

\section{RESULTS AND DISCUSSION}

The ${ }^{1} \mathrm{H}-\mathrm{NMR}$ spectra of $\mathrm{HNAN}$ and $\mathrm{HNAN}-\mathrm{NO}_{2}$ are shown in Fig. 1b. The chemical shifts of HNAN and HNAN- $-\mathrm{NO}_{2}$ are summarized as follows. For the HNAN, ${ }^{1} \mathrm{H}-\mathrm{NMR}$ (400 MHz, DMSO-D6, ppm): $\delta 16.18(\mathrm{~s}, 1 \mathrm{H}), \delta$ $9.83(\mathrm{~s}, 1 \mathrm{H}), \delta 8.58-8.56(\mathrm{~d}, 1 \mathrm{H}), \delta 8.25(\mathrm{~d}, 1 \mathrm{H}), \delta 8.05-$ $8.01(\mathrm{~m}, 1 \mathrm{H}), \delta 7.93-7.91(\mathrm{~d}, 1 \mathrm{H}), \delta 7.87-7.85(\mathrm{~d}, 1 \mathrm{H}), \delta$ 7.70-7.62 (m, 3H), $\delta 7.61-7.57(\mathrm{t}, 1 \mathrm{H}), \delta 7.42-7.38(\mathrm{t}, 1 \mathrm{H})$ and $\delta 7.17-7.15(\mathrm{~d}, 1 \mathrm{H})[36]$. For HNAN-NO ${ }_{2}: \delta 15.11(\mathrm{~s}$, $1 \mathrm{H}), \delta 9.87(\mathrm{~s}, 1 \mathrm{H}), \delta 8.73-8.71(\mathrm{~d}, 1 \mathrm{H}), \delta 8.57-8.55(\mathrm{~d}$, $1 \mathrm{H}), \delta 8.52-8.50(\mathrm{~d}, 1 \mathrm{H}), \delta 8.43-8.41(\mathrm{~d}, 1 \mathrm{H}), \delta 8.13-8.11$ $(\mathrm{d}, 1 \mathrm{H}), \delta 7.93-7.85(\mathrm{~m}, 4 \mathrm{H}), \delta 7.66-7.62(\mathrm{t}, 1 \mathrm{H}), \delta 7.48-$ $7.44(\mathrm{t}, 1 \mathrm{H})$ and $\delta 7.26-7.24(\mathrm{~d}, 1 \mathrm{H})$ (s: singlet, d: doublet, $\mathrm{m}$ : multiplet). The FTIR spectra of HNAN and HNAN$\mathrm{NO}_{2}$ are shown in Fig. 1c. For HNAN, the strong peak at $1615 \mathrm{~cm}^{-1}$ is assigned to the $\mathrm{C}=\mathrm{N}$ stretching vibration and the peak at $1310 \mathrm{~cm}^{-1}$ is due to the $\mathrm{C}-\mathrm{O}$ stretching vibration. The peaks in the $1450-950 \mathrm{~cm}^{-1}$ range arise from aromatic ring vibrations [37]. For HNAN- $\mathrm{NO}_{2}$, the peak at $1630 \mathrm{~cm}^{-1}$ is due to the $\mathrm{C}=\mathrm{N}$ stretching vibration, and the peaks at 1561 and $1327 \mathrm{~cm}^{-1}$ arise from the asymmetrical and symmetrical stretching vibration from $-\mathrm{NO}_{2}$, respectively [38]. It is concluded from the NMR and FTIR results that the Schiff base compounds were successfully synthesized. Fig. 1d shows the SEM image of the surface of HNAN/P(VDF-TrFE) composite. It is ob- served that the HNAN has a rod-like morphology and is well dispersed in the polymer matrix. The length and diameter of HNAN rods are $\sim 5$ um and $\sim 388 \mathrm{~nm}$, respectively. We also found that the rods are non-uniformly distributed in the thickness direction. The SEM image shown in Fig. 1d was observed from the upper surface of the dried composite films, and fewer HNAN rods are present at the lower surface that is formed by the glass plate during the drying process of the film as shown in Fig. S3. The results presented in Fig. S4 demonstrate the good flexibility of both composite films.

Fig. 2a shows the UV-Vis spectra of the HNAN and HNAN- $\mathrm{NO}_{2}$ powders. It is observed that HNAN displays a strong light absorption at wavelengths below $600 \mathrm{~nm}$. The modification of HNAN by the nitro group enhances the light absorption in a wider wavelength range $(<650 \mathrm{~nm})$. At higher wavelength up to $900 \mathrm{~nm}$ (IR light), both compounds still have weak absorption. The strong light absorption of the compounds enhances that of the composites. Fig. S5 shows that both composites have stronger absorption than $\mathrm{P}(\mathrm{VDF}-\mathrm{TrFE})$ film from the visible light to infrared light. The absorbed optical energy is converted into other types of energy such as thermal and electrical energies, as discussed below.

Fig. $2 \mathrm{~b}$ shows the temperature dependence of the dielectric properties of the polymer and composites, and the dielectric constant and loss of the composite showed almost no change in the vicinity of room temperature after the addition of the Schiff base. At a higher temperature, the dielectric loss increases due to the high conductivity of the Schiff base. As manifested by Fig. 2a, the Schiff base compounds are semiconductors with relatively small bandgaps (HNAN: $2.15 \mathrm{eV}, \mathrm{HNAN}-\mathrm{NO}_{2}: 2.02 \mathrm{eV}$ ) [39].
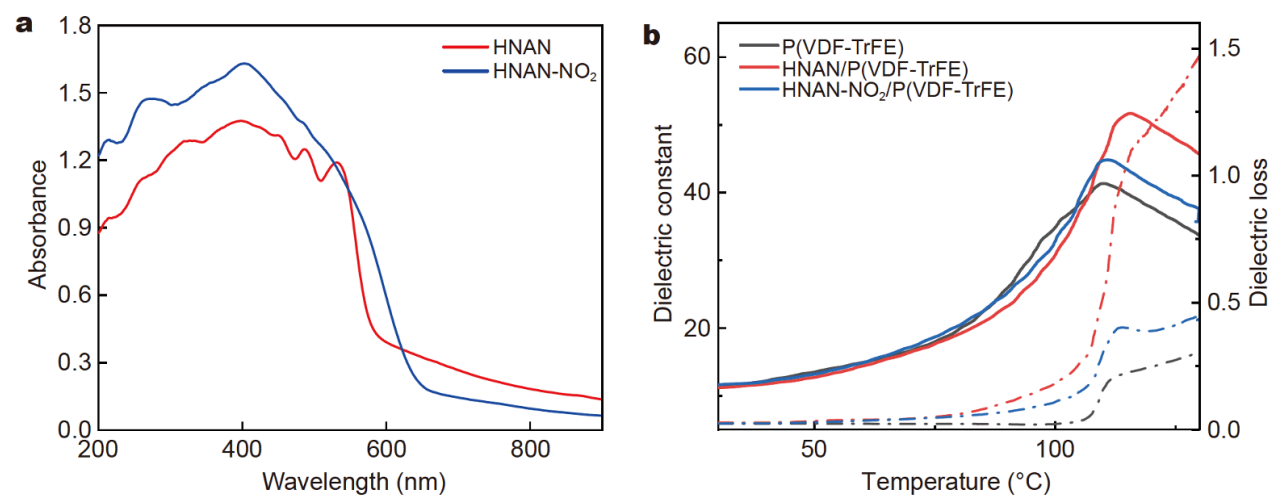

Figure 2 Characterization of the optical and dielectric properties of the Schiff base compounds and the composites. (a) The UV-Vis absorbance spectra of HNAN and HNAN-NO $\mathrm{N}_{2}$ powders. (b) Temperature dependence of the dielectric properties (at $\left.1 \mathrm{kHz}\right)$ of $\mathrm{P}(\mathrm{VDF}-\mathrm{TrFE})$ copolymer, HNAN/ $\mathrm{P}(\mathrm{VDF}-\mathrm{TrFE})$ composite and HNAN-NO$/ \mathrm{P}(\mathrm{VDF}-\mathrm{TrFE})$ composite. The solid and dotted lines show the results of the dielectric constant and dielectric loss, respectively. 
$\mathrm{P}(\mathrm{VDF}-\mathrm{TrFE})(70 / 30)$ is a typical ferroelectric polymer and the dielectric constant peak at $120^{\circ} \mathrm{C}$ indicates the Curie temperature of the polymer. The addition of HNAN and HNAN-NO ${ }_{2}$ into the copolymer slightly increases the Curie temperature compared with the pristine copolymer. This shift of the Curie temperature can be attributed to two reasons. First, there may exist interaction between the copolymer and Schiff base, and the Curie temperature of the copolymer can be increased by the interaction [40]. Second, the high conductivity of the Schiff base can also increase the apparent dielectric constant of the composites, as has been observed in composites with conductive fillers [41]. This affects the accurate determination of the Curie temperature of the polymer.

Fig. 3 shows the photoelectric responses of the composites of HNAN and HNAN-NO $\mathrm{N}_{2}$ with $\mathrm{P}(\mathrm{VDF}-\mathrm{TrFE})$ copolymer under illumination with IR and green light. Both composites show a relatively rapid photoelectric response upon exposure to light. The photovoltage quickly reached the maximum response, and then slowly decreased with continuous illumination. The maximum voltages for the composite with HNAN are $112.5 \mathrm{mV}$ under the near-infrared light and $7.6 \mathrm{mV}$ under green light (Fig. 3a and b). For the composite with HNAN-NO the voltages can reach $297.2 \mathrm{mV}$ under the near-infrared light and $39 \mathrm{mV}$ under green light (Fig. 3a and b). From Fig. 3, we can see that the modification of HNAN with $-\mathrm{NO}_{2}$ can strongly improve the photoelectric response of the composites, especially under green light. This can be attributed to the enhanced light absorption by the modification.

The photoelectric responses shown in Fig. $3 a$ and $b$ were measured in the composite films without subjecting to a poling process. We found that if a high electric field of $100 \mathrm{MV} \mathrm{m}^{-1}$, which is beyond the coercive field of $\mathrm{P}(\mathrm{VDF}-\mathrm{TrFE})$ (70/30) copolymer (the coercive field is determined from the polarization-electric field hysteresis curve shown in Fig. S6), was applied to the composite films to polarize the materials, the photoelectric response was greatly enhanced. As shown in Fig. $3 c$ and d, the maximum photovoltages of the poled HNAN composites were 710.6 and $85 \mathrm{mV}$ under the IR and green light, respectively; while for the poled $\mathrm{HNAN}-\mathrm{NO}_{2}$ composites, the maximum voltages were 1386 and $352.7 \mathrm{mV}$, respectively. It should be pointed out that due to the large
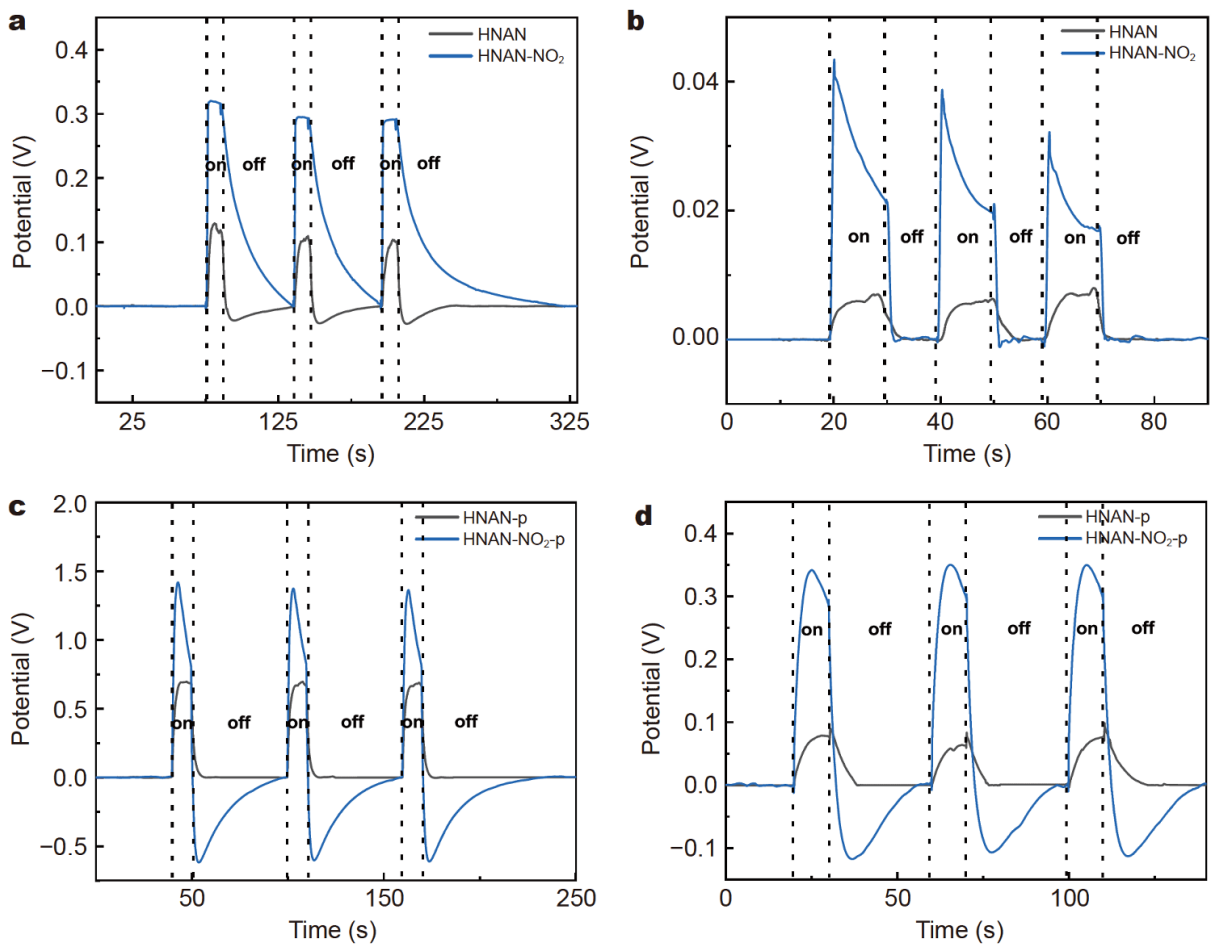

Figure 3 Photoelectric responses of HNAN and $\mathrm{HNAN}-\mathrm{NO}_{2}$ composites. Response of the unpoled film under (a) near-infrared illumination (power density of $133.9 \mathrm{~mW} \mathrm{~cm}^{-2}$ ) and (b) green light illumination (power density of $175 \mathrm{~mW} \mathrm{~cm}^{-2}$ ). Response of the poled film under (c) near-infrared illumination (power density of $27.2 \mathrm{~mW} \mathrm{~cm}^{-2}$ ) and (d) green light (power density of $175 \mathrm{~mW} \mathrm{~cm}^{-2}$ ). The "On" represents that the film is under the illumination and "Off" means that the light is shut off. The duration of light illumination is $10 \mathrm{~s}$. 
response of poled samples, an IR laser source with a lower power density $\left(27.2 \mathrm{~mW} \mathrm{~cm}^{-2}\right)$ was used to measure the photovoltages of the poled samples. Similarly, for poled samples, the composites with $\mathrm{HNAN}-\mathrm{NO}_{2}$ have a much higher photoelectric response than HNAN composites.

Because ferroelectric polymers are also pyroelectrics, it is understandable that the composites have a large photoelectric response under IR light [42]. On the other hand, both composites have relatively strong photoelectric response under green light and the mechanisms causing the response are explored. The $\mathrm{P}(\mathrm{VDF}-\mathrm{TrFE})$ copolymer should not exhibit a photoelectric response in the visible light range, and the response of the composite is attributed to the addition of Schiff base compounds. In the photoelectric curve shown in Fig. 3, when the green light is turned off, a sharp change of photovoltage can be observed. After that, the voltage slowly decays to zero. The sign of the voltage is different from that measured when the light is turned on. This behavior is reminiscence of the pyroelectric response of the ferroelectrics, by which a change of polarization is caused by a temperature change of the samples [43]. To determine whether the pyroelectric response is the mechanism underlying the photoelectric response, the temperature of the HNAN$\mathrm{NO}_{2}$ composites during green light illumination was recorded using an infrared camera (as schematically shown in Fig. 4a), and the results are shown in Fig. 4b. It is observed that the temperature of the composite increases after light illumination and this temperature change can be as high as $5^{\circ} \mathrm{C}$ for the HNAN-NO ${ }_{2}$ composites. This implies that the green light absorbed by the Schiff base compounds is converted into thermal energy (the photothermal effect) [44]. Therefore, the coupling of the photothermal effect of the Schiff base and the pyroelectric

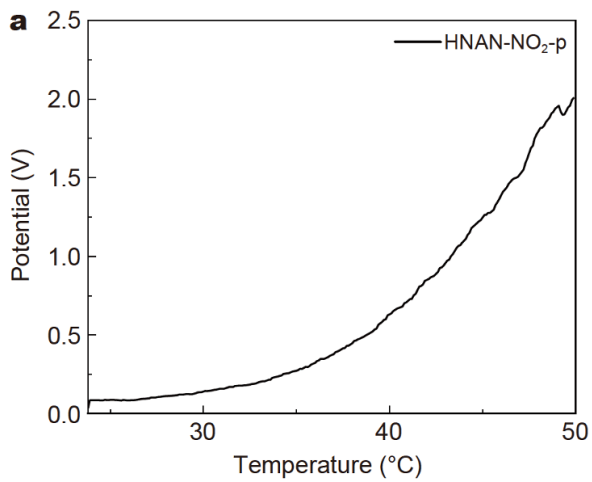

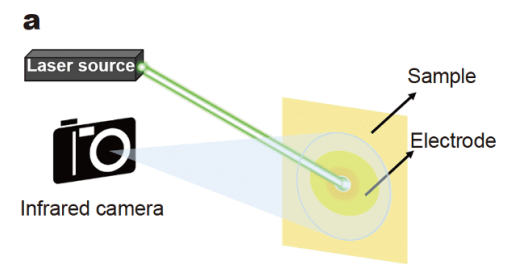

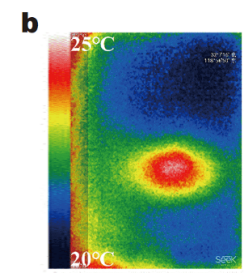

Figure 4 (a) Schematic diagram of the experimental setup for the temperature measurement of the samples under light illumination. Green light is irradiated on the central part of the samples and the infrared camera records the temperature change of the samples. (b) After a stable temperature value is reached, the temperature of the poled $\mathrm{HNAN}-\mathrm{NO}_{2} / \mathrm{P}(\mathrm{VDF}-\mathrm{TrFE})$ composite under green light illumination is recorded by an infrared camera. The temperature of the sample is represented by the color with the temperature scale bar shown to the left of the image.

response of the ferroelectric polymer is believed to be one mechanism contributing to the photoelectric response under green light illumination. To support the proposed photoelectric mechanism, the temperature dependence of the voltage (the pyroelectric response) was measured with the result shown in Fig. 5a. For the heating rate of $2^{\circ} \mathrm{C} \mathrm{min}^{-1}$, the voltage change is approximately $0.05 \mathrm{~V}$ from 24 to $26^{\circ} \mathrm{C}$. Under green light illumination, the rate of the temperature change of the poled $\mathrm{HNAN}-\mathrm{NO}_{2}$ composites can be obtained by measuring the time-dependent temperature of the sample and the result is shown in Fig. 5b. The result was obtained from the movie recorded by an infrared camera. The temperature change rate is estimated to be $\sim 12^{\circ} \mathrm{C} \min ^{-1}$ under green light illumination. Because the conditions of the measurement are the same as those used to measure the photoelectric response, we can use the temperature change to estimate the pyroelectric response induced by the photothermal

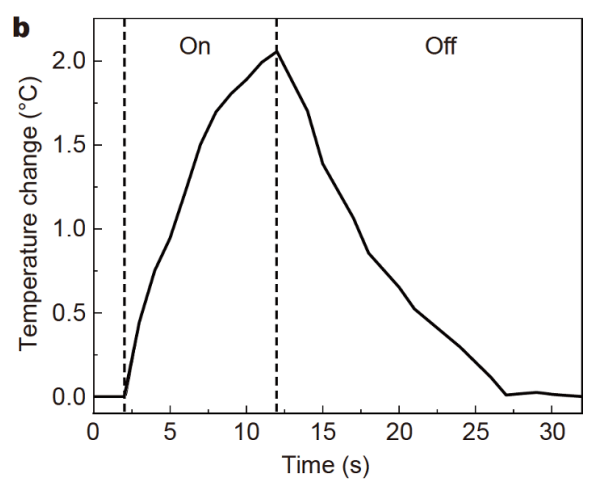

Figure 5 (a) Temperature-dependent of the pyroelectric voltage of the poled HNAN-NO $2 / \mathrm{P}(\mathrm{VDF}-\mathrm{TrFE})$ composite heated at a rate of $2^{\circ} \mathrm{C}$ min ${ }^{-1}$. (b) Temperature change as a function of time for the poled $\mathrm{HNAN}-\mathrm{NO}_{2} / \mathrm{P}(\mathrm{VDF}-\mathrm{TrFE})$ composite under green light illumination. "On" means that the film is under illumination and "Off" means that the light is shut off. The duration of illumination is approximately $10 \mathrm{~s}$. The measurement conditions are the same as those for the photoelectric response measurements. 
effect under green light illumination. The pyroelectric voltage is proportional to the rate of the temperature change and the voltage generated by the poled HNAN$\mathrm{NO}_{2}$ composites under green light illumination is estimated to be $\sim 300 \mathrm{mV}$ at room temperature due to the photothermal effect. The voltage is close to the measured photoelectric response of the composite $(\sim 353 \mathrm{mV}$, Fig. 3d).

The rise time $t_{\mathrm{r}}$ (the time required for the response rising from $10 \%$ to $90 \%$ of the peak value) can be used to characterize the speed of the photoelectric response and was $2-4 \mathrm{~s}$ for the composites including the Schiff base compounds according to the results presented in Fig. 3. Because a thermal transfer process is involved to generate the photoelectric response, some extrinsic factors, such as the thickness of the tested sample, also affect the thermal transfer and hence the speed of the photoelectric response [45]. Therefore, the response speed is not an intrinsic property of the composites.

For ferroelectric polymers, poling can align the spontaneous polarization and increase the pyroelectric response, resulting in the enhanced photoelectric response in the poled composites. While theoretically, the nonpoled composites should not exhibit a pyroelectric response, the pyroelectric response observed in the nonpoled samples may originate from the residual polarity caused by the local inhomogeneity produced during film fabrications. An examination of the photovoltage curves of the non-poled composites shows that after the light is turned on, the voltages tend to approach a non-zero constant value that cannot be explained by the pyroelectric effect, because the pyroelectric response becomes zero for a constant temperature. The nearly constant voltage may originate from the photovoltaic effect of the Schiff base compounds or the photo-thermoelectric effect due to the inhomogeneous temperature in the composites under light illumination [46]. The slow decay of the photovoltage after the light is turned off in some samples (Fig. 3a) may be caused by the photo-thermoelectric effect, because the poor heat dissipation of the polymer leads to a non-uniform temperature distribution in the film even after the light is turned off.

We also observed that the generated photovoltage of the composites depends on the light incidence direction. Typically, the photovoltage measured for the illumination of the top surface (Fig. 1d) that has a higher concentration of the Schiff base is larger than that measured when the opposite surface is illuminated, as shown in Fig. S7. This reflects the importance of the concentration of the Schiff base for the photoelectric response of the compo- sites. Due to the strong light absorption of the Schiff base, the incident light intensity will be attenuated in the filmthickness direction. Therefore, the amount of the Schiff base existing in the certain depth from the illuminated surface is important for the magnitude of the measured photovoltage.

\section{CONCLUSIONS}

In summary, Schiff base compounds/P(VDF-TrFE) composites with high photoelectric response were successfully prepared. The composites show good photoelectric responses under IR $(915 \mathrm{~nm})$ and green $(532 \mathrm{~nm})$ light illumination. Enhanced light absorption and photoelectric response were obtained after HNAN was modified by the nitro functional group to obtain HNAN$\mathrm{NO}_{2}$. We also found that poling of the composites increased the photovoltage by 4 times under IR light and by at least 5 times under green light illumination. The maximum photovoltage values of 1386 and $352.7 \mathrm{mV}$ were obtained under irradiation with the near-infrared and green light, respectively. The photoelectric response under green light was found to be due to the coupling of the photothermal effect of the Schiff base and the pyroelectric effect of the polymer. Their high photoelectric response makes these composites good candidate materials for the application in artificial retina devices. Because the materials generate a photoelectric response under both visible and IR light, the sensing capability of the artificial retina can be enhanced to a wider wavelength range compared to that of the human retina.

Received 29 April 2020; accepted 9 September 2020;

published online 12 November 2020

1 Goetzberger A, Hebling C. Photovoltaic materials, past, present, future. Sol Energy Mater Sol Cells, 2000, 62: 1-19

2 Parida B, Iniyan S, Goic R. A review of solar photovoltaic technologies. Renew Sustain Energy Rev, 2011, 15: 1625-1636

3 Polman A, Knight M, Garnett EC, et al. Photovoltaic materials: Present efficiencies and future challenges. Science, 2016, 352: aad4424

4 Munshi AH, Kephart J, Abbas A, et al. Polycrystalline CdSeTe/ CdTe absorber cells with $28 \mathrm{~mA} / \mathrm{cm}^{2}$ short-circuit current. IEEE J Photovoltaics, 2018, 8: 310-314

5 Zhao Y, Sun Y, He Y, et al. Design and fabrication of six-volt vertically-stacked GaAs photovoltaic power converter. Sci Rep, 2016, 6: 38044

6 Duan J, Xu H, Sha WEI, et al. Inorganic perovskite solar cells: an emerging member of the photovoltaic community. J Mater Chem A, 2019, 7: 21036-21068

7 Gong X, Tong M, Xia Y, et al. High-detectivity polymer photodetectors with spectral response from $300 \mathrm{~nm}$ to $1450 \mathrm{~nm}$. Science, 2009, 325: 1665-1667

8 Jansen-van Vuuren RD, Armin A, Pandey AK, et al. Organic 
photodiodes: The future of full color detection and image sensing. Adv Mater, 2016, 28: 4766-4802

9 Koppens FHL, Mueller T, Avouris P, et al. Photodetectors based on graphene, other two-dimensional materials and hybrid systems. Nat Nanotech, 2014, 9: 780-793

10 Özmert E, Arslan U. Retinal prostheses and artificial vision. Turkish J Ophthalmol, 2019, 49: 213-219

11 Funatsu E, Hara K, Toyoda T, et al. An artificial retina chip made of a $128 \times 128$ pn-np variable-sensitivity photodetector array. IEEE Photon Technol Lett, 1995, 7: 188-190

12 Kyuma K, Lange E, Ohta J, et al. Artificial retinas-fast, versatile image processors. Nature, 1994, 372: 197-198

13 Wickelgren I. Biomedical engineering: A vision for the blind. Science, 2006, 312: 1124-1126

14 Lange E, Funatsu E, Hara K, et al. Artifical retina devices-fast front ends for neural image processing systems. In: Proceedings of 1993 International Conference on Neural Networks (IJCNN-93-Nagoya, Japan), 1993, 1: 801-804

15 Chen X, Pan S, Feng PJ, et al. Bioinspired ferroelectric polymer arrays as photodetectors with signal transmissible to neuron cells. Adv Mater, 2016, 28: 10684-10691

16 Konnerth A, Orkand RK. Voltage-sensitive dyes measure potential changes in axons and glia of the frog optic nerve. NeuroSci Lett, 1986, 66: 49-54

17 Shen DS, Wagner S. Transient photocurrent in hydrogenated amorphous silicon and implications for photodetector devices. J Appl Phys, 1996, 79: 794-801

18 Pan J, Deng W, Xu X, et al. Photodetectors based on smallmolecule organic semiconductor crystals. Chin Phys B, 2019, 28: 38102

19 Matt GJ, Levchuk I, Knüttel J, et al. Sensitive direct converting Xray detectors utilizing crystalline $\mathrm{CsPbBr}_{3}$ perovskite films fabricated via scalable melt processing. Adv Mater Interfaces, 2020, 7: 1901575

20 Hu W, Cong H, Huang W, et al. Germanium/perovskite heterostructure for high-performance and broadband photodetector from visible to infrared telecommunication band. Light Sci Appl, 2019, 8: 106

21 Wu D, Wang Y, Zeng L, et al. Design of 2D layered $\mathrm{PtSe}_{2}$ heterojunction for the high-performance, room-temperature, broadband, infrared photodetector. ACS Photonics, 2018, 5: 3820-3827

22 Weiss DS, Abkowitz M. Advances in organic photoconductor technology. Chem Rev, 2010, 110: 479-526

23 Jia R, Wu X, Deng W, et al. Unraveling the mechanism of the persistent photoconductivity in organic phototransistors. Adv Funct Mater, 2019, 29: 1905657

$24 \mathrm{Wu} \mathrm{D}$, Guo J, Du J, et al. Highly polarization-sensitive, broadband, self-powered photodetector based on graphene/PdSe 2 /germanium heterojunction. ACS Nano, 2019, 13: 9907-9917

25 Wu E, Wu D, Jia C, et al. In Situ fabrication of 2D WS $2 /$ Si type-II heterojunction for self-powered broadband photodetector with response up to mid-infrared. ACS Photonics, 2019, 6: 565-572

26 Bushuyev OS, Singleton TA, Barrett CJ. Fast, reversible, and general photomechanical motion in single crystals of various azo compounds using visible light. Adv Mater, 2013, 25: 1796-1800

27 Kim J, Lee JH, Ryu $\mathrm{H}$, et al. High-performance piezoelectric, pyroelectric, and triboelectric nanogenerators based on P(VDFTrFE) with controlled crystallinity and dipole alignment. Adv Funct Mater, 2017, 27: 1700702

28 Liu J, Zhou Y, Hu X, et al. Flexoelectric effect in PVDF-based copolymers and terpolymers. Appl Phys Lett, 2018, 112: 232901

29 Liu X, Chen H, Tan S. Overview of high-efficiency organic photovoltaic materials and devices. Renew Sustain Energy Rev, 2015, 52: $1527-1538$

30 Zhou J, Wan X, Liu Y, et al. Small molecules based on benzo[1,2$\mathrm{b}: 4,5-\mathrm{b}^{\prime}$ ]dithiophene unit for high-performance solution-processed organic solar cells. J Am Chem Soc, 2012, 134: 16345-16351

31 Aliane A, Benwadih M, Bouthinon B, et al. Impact of crystallization on ferro-, piezo- and pyro-electric characteristics in thin film P(VDF-TrFE). Org Electron, 2015, 25: 92-98

32 Chang WC, Wang $\mathrm{AB}$, Lee $\mathrm{CK}$, et al. Photoconductive piezoelectric polymer made from a composite of $\mathrm{P}(\mathrm{VDF}-\mathrm{TrFE})$ and TiOPc. Ferroelectrics, 2013, 446: 9-17

33 Lan T, Chen W. Hybrid nanoscale organic molecular crystals assembly as a photon-controlled actuator. Angew Chem Int Ed, 2013, 52: 6496-6500

34 Jeevadason AW, Murugavel KK, Neelakantan MA. Review on Schiff bases and their metal complexes as organic photovoltaic materials. Renew Sustain Energy Rev, 2014, 36: 220-227

35 Petrus ML, Bouwer RKM, Lafont U, et al. Small-molecule azomethines: organic photovoltaics via Schiff base condensation chemistry. J Mater Chem A, 2014, 2: 9474-9477

36 Sahana A, Banerjee A, Lohar S, et al. Naphthalene based highly selective OFF-ON-OFF type fluorescent probe for $\mathrm{Al}^{3+}$ and $\mathrm{NO}_{2}{ }^{-}$ ions for living cell imaging at physiological $\mathrm{pH}$. Inorg Chim Acta, 2013, 398: 64-71

37 Ghosh K, Kumar R, Kumar K, et al. Reactivity of nitric oxide with ruthenium complexes derived from bidentate ligands: structure of a ruthenium nitrosyl complex, photoinduced generation and estimation of nitric oxide. RSC Adv, 2014, 4: 43599-43605

38 Arjunan V, Balamourougane PS, Saravanan I, et al. Investigation of the structural and harmonic vibrational properties of 2-nitro-, 4nitro- and 5-nitro- $m$-xylene by $a b$ initio and density functional theory. Spectrochim Acta Part A-Mol Biomol Spectr, 2009, 74: 798-807

39 L. Y, M. N, P. AS, et al. Optical properties and ionic conductivity studies of an $8 \mathrm{MeV}$ electron beam irradiated poly(vinylidene fluoride-co-hexafluoropropylene) $/ \mathrm{LiClO}_{4}$ electrolyte film for optoelectronic applications. RSC Adv, 2018, 8: 15297-15309

40 Goissis G, Piccirilli L, De Guzzi Plepis AM, et al. Preparation and characterization of anionic collagen: $\mathrm{P}(\mathrm{VDF} / \mathrm{TrFE})$ composites. Polym Eng Sci, 1999, 39: 474-482

41 Dang ZM, Yuan JK, Yao SH, et al. Flexible nanodielectric materials with high permittivity for power energy storage. Adv Mater, 2013, 25: 6334-6365

42 Dubois JC, Robin P. Ferroelectric polymers and IR detection. Ferroelectrics, 1995, 171: 253-258

43 Sharma M, Vaish R, Chauhan VS. Development of figures of merit for pyroelectric energy-harvesting devices. Energy Technol, 2016, 4: $843-850$

44 Liu S, Liu Y, Hu C, et al. Boosting the antitumor efficacy over a nanoscale porphyrin-based covalent organic polymer via synergistic photodynamic and photothermal therapy. Chem Commun, 2019, 55: 6269-6272

45 Yang D, Ma D. Development of organic semiconductor photodetectors: From mechanism to applications. Adv Opt Mater, 2019, 7: 1800522

46 He M, Lin YJ, Chiu CM, et al. A flexible photo-thermoelectric nanogenerator based on $\mathrm{MoS}_{2} / \mathrm{PU}$ photothermal layer for infrared light harvesting. Nano Energy, 2018, 49: 588-595 
Acknowledgements This research was supported by the National Key Research and Development Program of China (2017YFA0701301), and the National Natural Science Foundation of China (51373161 and 51672261).

Author contributions $\quad \mathrm{Chu} \mathrm{B}$, Shen $\mathrm{Q}$ and Liu J conceived the idea; Liu J, Yi K and Wang $\mathrm{Z}$ fabricated the samples and characterized the structure and electrical properties of the samples; Zhang $Z$ and Qi $Y$ helped to measure the photovoltaic response of the samples.; Chen $\mathrm{P}$ helped to obtain the FTIR and H-NMR spectra. All authors contribute to the general discussion.

Conflict of interest There are no conflicts to declare.

\section{Supplementary information} online version of the paper.

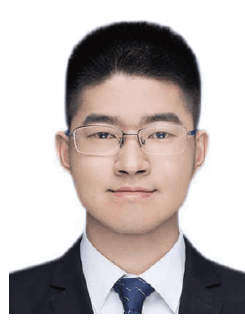

Jie Liu was born in Liaoning province in 1993. $\mathrm{He}$ received the $\mathrm{BE}$ degree in polymer science and engineering from the University of Science of and Technology of China in 2015. Currently he is a $\mathrm{PhD}$ candidate in material science and engineering at the University of Science and Technology of China. His research is focused on the electrical properties of PVDF-based polymers.

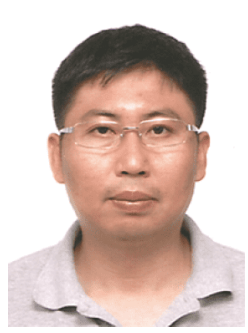

Baojin Chu received his $\mathrm{PhD}$ from Pennsylvania State University in 2008. After post-doctoral research in the Materials Research Institute at Pennsylvania State University, he worked as a research scientist in CAPE Lab at South Dakota School of Mines and Technology. Currently, he is a faculty at the University of Science and Technology of China (since 2012). His research interests include ferroelectricity, piezoelectricity, and flexoelectricity of materials, and related applications

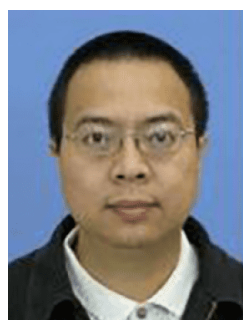

Qundong Shen received his BSc in polymer materials and $\mathrm{PhD}$ degree in polymer physics and chemistry from Nanjing University. He is presently a professor at the Department of Polymer Science and Engineering, School of Chemistry and Chemical Engineering, Nanjing University. He has been active in the design and syntheses of functional polymers. His current research focuses on ferroelectric polymers for information storage and energy utilization, as well as conjugated polymers for biomedical applications.

\section{在宽光谱范围内具有强光电响应的全有机复合 材料}

刘杰 $^{1 \dagger}$, 易可望 ${ }^{1 \dagger}$, 王兆鹏 ${ }^{1 \dagger}$, 祁瑜聪 ${ }^{2}$, 张子劼 ${ }^{2}$, 陈攀 ${ }^{1}$, 沈群东 ${ }^{2}$, 初宝进 ${ }^{1 *}$

摘要 本文合成了席夫碱化合物 2-hydroxynaphthylidene-1' naphthylamine (HNAN) 和硝基改性的HNAN (HNAN- $\left.\mathrm{NO}_{2}\right)$. 这两 种化合物在可见光 $(<650 \mathrm{~nm})$ 下显示出强吸光性. 我们将这些化合 物与Poly(vinylidene fluoride-trifluoroethylene) (P(VDF-TrFE)) 铁 电聚合物复合, 得到了在可见光和红外光下具有高光电响应的复 合材料. 研究发现, 利用HNAN的硝基改性或高电场下对复合材料 进行极化可以大大增强复合材料的光电响应. 复合材料在近红外 光(波长 $915 \mathrm{~nm}$ )下可产生 $1386 \mathrm{mV}$ 的光电压, 而在绿光 $(532 \mathrm{~nm}$ )下 可产生 $352.7 \mathrm{mV}$ 的光电压. 本文还探索了复合材料在绿光下的光 电响应的产生机理, 发现其响应主要源于席夫碱的光热效应和铁 电聚合物的热释电效应之间的耦合作用. 该复合材料可作为光电 材料应用于下一代人工视网膜的光响应材料, 并使人工视网膜能 够感知的光波段从可见光扩展到红外光. 